\title{
LA JURISDICCIÓN CONSTITUCIONAL Y LAS POSIBILIDADES DE CONCRETIZACIÓN DE LOS DERECHOS FUNDAMENTALES SOCIALES
}

\author{
LENIO LUIZ STRECK \\ Profesor Titular de Derecho Constitucional \\ Universidad Unisinos (Brasil)
}

SUMARIO

I. El constitucionalismo contemporáneo y la tensión inexorable entre jurisdicción y legislación: el nuevo papel del Derecho en el Estado Democrático de Derecho.

II. Constitución, Derecho y Democracia: las dimensionales procesales y substantivasun debate necesario.

III. El papel de la hermenéutica en ese rompimiento paradigmático necesario y el nuevo papel de la jurisdicción constitucional en la concretización de los derechos fundamentales-sociales.

IV. A modo de conclusión.

\section{EL CONSTITUCIONALISMO CONTEMPORÁNEO Y LA TENSIÓN INEXORABLE ENTRE JURISDICCIÓN Y LEGISLACIÓN: EL NUEVO PAPEL DEL DERECHO EN EL ESTADO DEMOCRÁTICO DE DERECHO}

La discusión sobre el constitucionalismo contemporáneo es una tarea que todavía se impone. El constitucionalismo no murió. Las nociones de fuerza normativa de la Constitución y de Constitución compromisaria no pueden ser relegadas a un segundo plano, especialmente en países en los que las promesas de la modernidad contempladas en los textos constitucionales, carecen de una mayor efectividad. 
En este sentido, uno de los puntos fundamentales para un mejor entendimiento/enfrentamiento de toda esa problemática exige una discusión sobre el papel del Derecho (por lo tanto, de la Constitución) y de la jurisdicción constitucional en el Estado Democrático de Derecho, así como de las condiciones que posibiliten la implementación/concretización de los derechos fundamentales-sociales ${ }^{1}$ a partir de ese nuevo paradigma de Derecho y de Estado. Aún más, resulta imprescindible discutir la crisis del Derecho, del Estado y de la dogmática jurídica, y sus reflejos en la sociedad a partir del papel de la justicia constitucional en ese nuevo paradigma.

Hay que tener bien claro que el surgimiento del paradigma del Estado Democrático de Derecho trae implícita la problemática de la tensión entre jurisdicción y legislación. Como asevera Bachof:

[...]As normas constitucionais em muitos casos não podem ser interpretadas sem o recurso a valorações politicas: tais valorações, porém, são sempre, até em determinado ponto, subjetivas. Assim, verificar-se-á sempre inevitavelmente uma certa relação tensionante entre o direito e a política. O juiz constitucional aplica certamente direito; mas a aplicação deste direito acarreta consigo necessariamente que aquele que a faz proceda a valorações políticas ${ }^{2}$.

La evolución de la Teoría del Estado implica el surgimiento de la "politización" de la Constitución. Del normativismo constitucional saltamos para la Teoría Material de la Constitución. Este es el momento de la imbricación entre Constitución y política. Y el Estado Democrático de Derecho es el locus privilegiado de este acontecimiento. La dimensión política de la Constitución no es una dimensión separada, sino el punto en el que convergen las dimensiones democrática (formación de la unidad política), liberal (coordinación y limitación del poder estatal) y social (configuración social de las condiciones de vida) de aquello que se puede denominar de "esencia" del constitucionalismo de la segunda posguerra. Por lo tanto, ninguna de las funciones puede ser

1 Utilizo la expresión "derechos fundamentales-sociales" porque los derechos sociales son derechos fundamentales prestacionales. En este sentido, la preocupación primordial es con la esfera de los derechos fundamentales a prestaciones, que tiene por objeto una conducta positiva por parte del destinatario, consistente, por norma, en una prestación de naturaleza fáctica o normativa. Así, mientras los derechos de defensa se identifican por su naturaleza preponderantemente negativa, teniendo por objeto abstenciones del Estado, los derechos sociales prestacionales (lo que está en causa aquí es precisamente la dimensión positiva, que no excluye una faceta de cuño negativo) tiene por objeto precipuo una conducta positiva del Estado o particulares destinatarios de la norma, según lo que muy bien señala Ingo SARLET (Direitos Fundamentais, Porto Alegre, Livraria do Advogado, 2003, p. 272 y siguientes).

2 "Las normas constitucionales en muchos casos no pueden ser interpretadas sin el recurso a valoraciones politicas: tales valoraciones, sin embargo, son siempre, hasta determinado punto, subjetivas. Así, se verificará siempre inevitablemente una cierta relación tensa entre el derecho y la política. El juez constitucional aplica ciertamente derecho; pero la aplicación de este derecho determina necesariamente que aquel que la hace proceda a valoraciones políticas". Cfe. Otto BACHOF. Estado de Direito e Poder Político. Boletín de la Facultad de Derecho de Coimbra, vol. LVI Coimbra: Coimbra Editora, 1996, p. 10. 
entendida aisladamente. Es exactamente por eso que Hans Peter Schneider dice que la Constitución es derecho político: de, sobre y para lo político ${ }^{3}$.

Esa es la razón de la importancia que debe ser dada a la discusión sobre el tipo de justicia constitucional encargada de realizar el control de la constitucionalidad del ordenamiento jurídico de cada país. El desplazamiento del polo de tensión relacionado con la clásica cuestión de la división-separación de Poderes recibe, de este modo, una nueva concepción a partir del establecimiento de tribunales que no hacen parte - stricto sensu- de la cúpula del Poder Judicial ${ }^{4}$ trayendo consigo, en su estructuración, la efectiva participación del Poder Legislativo.

No hay duda, entonces, que ese nuevo modelo de justicia constitucional - el modelo de tribunales ad boc introducido stricto sensu inicialmente en Austria y reafirmado en las Constituciones de Italia, Alemania, Portugal y España, para mencionar solo las principales - deja marcas indelebles en el constitucionalismo contemporáneo. La doctrina alemana, especialmente, en gran medida basada en el estudio de la Ley Fundamental y de la actuación del Bundesverfassungsgericht, influenció todo el pensamiento constitucional, principalmente en lo que concierne al estudio de la eficacia de los derechos fundamentales y de los mecanismos interpretativos que sustenta(ba)n las tesis provenientes de la idea de fuerza normativa del texto constitucional y su carácter directriz.

Pero más que eso, obsérvense, por un lado, las Constituciones de España y Portugal, que sirvieron de modelo para la Constitución brasileña de 1988, y, por otro lado, el propio tipo de tribunal constitucional instituido en otros países de Europa (lamentablemente no seguido por Brasil). En este sentido, parece que no hay duda en cuanto al papel decisivo asumido por los tribunales constitucionales en los diversos países en que fueron implementados. La función interventiva y correctiva de la legislación hecha por los tribunales constitucionales, aparece nítidamente a través de los diversos tipos de decisiones que han emanado (manipulativas, constructivas, complementares, reductivas, aditivas, para citar solamente algunas modalidades).

De este modo, es razonable afirmar, que la fuerza normativa de la Constitución - $-\mathrm{y}$, si así se quisiera, su papel directriz y compromisario- siempre tuvo una relación directa con la actuación de la justicia constitucional en la defensa de la implementación de los valores substanciales previstos en la Ley Mayor. Para tal constatación, basta un examen en la jurisprudencia de los tribunales constitucionales, principalmente la de los primeros años, de países como Alemania, España y Portugal, sin olvidar, aquí, la importancia del así denomi-

3 Las tres dimensiones de las funciones de la Constitución pueden ser encontradas en SCHNEIDER, Hans Peter. La Constitución-Función y Estructura. In: Democracia y Constitución. Madrid, CEC, 1991, pp. 35-52.

4 Regístrese que Brasil, durante el proceso constituyente de 1986-88, optó por permanecer con el modelo del Poder Judicial (review) de inspiración norteamericana, rechazando la fórmula de los tribunales constitucionales, de tanto éxito en Europa continental. 
nado "activismo judicial" de la Supreme Court de los Estados Unidos, por ejemplo, del "Tribunal Warren".

Claro que siempre existen temores en relación con ese "intervencionismo" de la justicia constitucional, cuestión que aparece nítidamente en las posturas de autores de nítido perfil procedimentalista como Jürgen Habermas, John Hart Ely e Ingeborg Maus ${ }^{5}$, para citar algunos, como será detallado más adelante. Como contrapunto de cariz substancialista, vale recordar lo expresado por García Herrera ${ }^{6}$ para quien cuando se defienden los principios constitucionales no se hace política sino defensa jurisdiccional de la Constitución ${ }^{7} . \mathrm{Y}$, además,

[...] a quem disser que a Constituição assim cai na utopia sempre se poderá replicar com P. Lucas Verdú que 'todas as realidades de hoje foram utopias de ontem.' A 'Constituição justa' pode ser utópica, mas, como muito bem observa Muguerza, quando uma utopia admite uma remota possibilidade de realização, o seu defeito não é ser uma utopia, mas precisamente o facto de não deixar de o ser. Por nosso lado, não hesitaremos em subscrever a 'profecia' de Macpherson: 'Só sobreviverão as sociedades que melhor possam satisfazer as exigências do próprio povo no que concerne à igualdade de direitos humanos e à possibilidade de todos os seus membros lograrem uma vida plenamente humana's.

Nunca es demás repetir que el Estado Democrático de Derecho se asienta en dos pilares: la democracia y los derechos fundamentales. No hay democra-

5 La jurista alemana ha hecho agudas críticas al intervencionismo de los tribunales constitucionales, a partir de una crítica a la lectura moral de la Constitución hecha por autores como Dworkin, que, según ella, oculta moralmente un "decisionismo" judicial. Aunque no asuma la radicalidad procedimentalista de autores como Habermas y Ely, es posible afirmar que Maus se aproxima, en parte, a Habermas, cuando sustenta que los Tribunales Constitucionales no deben ser elevados a la categoría de protectores de una orden suprapositiva de valores (cf. MAUS, Ingeborg; O Judiciário como Superego da Sociedade-Sobre o Papel da Atividade Jurisprudencial na "Sociedade Órfã". Trad. de Martonio MONT'ALVERNE BARRETO LIMA y Paulo Antonio DE MENEZES ALBUQUERQUE. In: Anuário dos Cursos de Pós-Graduação em Direito da Faculdade de Direito de Recife n. 11. Recife, UFPE, 2000, pp. 125 y sig.

6 Cfe. GARCÍA HERRERA, Miguel Ángel. Prólogo a la segunda edición del Manual de Derecho Constitucional. Benda, Maihofer, Vogel, Hesse, Heide. Madrid, Marcial Pons, 2001.

7 Tal vez por eso algunos autores alegan que el Tribunal Constitucional es el protector último de los derechos fundamentales. En este sentido, Juan Antonio Doncel Luengo, In: El modelo español de justicia constitucional. Las decisiones más importantes del tribunal constitucional. Sub judice, enero/junio, 20/21. Coimbra, Docjuris, 2001, pp. 79 y sig.

8 „...) a quien diga que la Constitución así cae en la utopía siempre se le podrá replicar con P. Lucas Verdú que 'todas las realidades de hoy fueron utopías de ayern; La 'Constitución justa' puede ser utópica, pero, como muy bien observa Muguerza, cuando una utopia admite una remota posibilidad de realización, su defecto no es ser una utopia, sino precisamente el hecho de no dejar de serlo. De nuestra parte, no vacilaremos en suscribir la 'profecía' de Macpherson: 'Solamente van a sobrevivir las sociedades que mejor puedan satisfacer las exigencias del propio pueblo en lo que concierne a igualdad de derechos humanos y a la posibilidad de que todos sus miembros logren una vida plenamente humana." Cfe. CABRAL PINTO, Luzia Marques da Silva. Os limites do poder constituinte e a legitimidade material da Constituição. Coimbra, Coimbra Editora, 1994, p. 218 e 219 
cia sin el respeto y la realización de los derechos fundamentales sociales, y no hay derechos fundamentales sociales - en el sentido que se le da tradicionalmente- sin democracia. Hay, así, una co-pertenencia entre ambos. El constitucionalismo contemporáneo pensó en esa convivencia necesaria entre el régimen democrático y la realización de los derechos previstos en las Constituciones.

Mientras tanto, parece inexorable que ocurra una cierta tensión entre los Poderes del Estado a partir de la siguiente ecuación: de un lado, textos constitucionales forjados en la tradición de la segunda pos-guerra estipulando y señalando la necesidad de la realización de los derechos fundamentales-sociales; por otro, la difícil convivencia entre los Poderes del Estado, elegidos (Ejecutivo y Legislativo) por mayorias no siempre concordantes con los dictámenes constitucionales. Junto a esa problemática, está la cuestión de la legitimidad del Poder Judicial (justicia constitucional) desconstituir actos normativos del Poder Ejecutivo o declarar la inconstitucionalidad de leyes votadas por el parlamento elegido democráticamente por el pueblo.

Esa tensión asume contornos más graves cuando el sistema se depara con decisiones del Poder Judicial consideradas "invasoras de subsistemas" o rotuladas como típicas decisiones que "judicializan la política", como es el caso de sentencias emanadas de los jueces y tribunales brasileños determinando la inclusión/creación de vacantes en escuelas públicas; el suministro de remedios en base al artículo 196 de la Constitución; la extensión, basada en el principio del insomnio, de beneficios a categorías de trabajadores no contempladas en acto normativo; el problema de las ocupaciones de tierras improductivas por movimientos sociales que claman por el cumplimiento del dispositivo constitucional que establece la función social de la propiedad, solamente para citar algunos ejemplos.

Ese debate parece interminable. Al final, ¿aún es posible hablar de Constitución compromisaria? ¿Puede un texto constitucional determinar el actuar político-estatal? La voluntad general popular, representada por mayorías eventuales, ¿puede alterar substancialmente el contenido de la Constitución en aquello que es su núcleo político? ¿Incluso es posible hablar de soberanía de los Estados? ¿Cuáles son los límites del "Constituir" de la Constitución? Muy a pesar de la notoria complejidad del problema, parece posible establecer las bases mínimas para su comprensión. En efecto, ante todo, hay que entender, que la Constitución más allá de ser el eslabón del contenido que une solítica y derecho" en un determinado Estado, es también un (eficiente) remedio contra mayorías. Y al constituirse en remedio contra mayorias, eventuales o no, la Constitución, como explicitación del contrato social, trae implícito un núcleo político que solo puede ser extirpado/solapado a partir de una ruptura institucional.

Esta es la regla del juego democrático y el costo que representa vivir bajo la égida del Estado Democrático de Derecho. Y es de esa intrincada ingeniería política que surge un nuevo papel para el Derecho y, en consecuencia, para la Constitución. No está demás recordar que, en el Estado Liberal, el Derecho te- 
nía la función ordenadora y fijadora de las bases de la legislación para contraponerse al antiguo régimen y todo lo que él representaba. Para esa tarea, había que superar el jusnaturalismo. El triunfo de la voluntad general trae implícito un desplazamiento de la esfera del Poder Ejecutivo (que representa el absolutismo) hacia la voluntad popular-revolucionaria (representada en el Legislativo), que triunfó. Sin ninguna legitimidad, se coloca el Judicial al margen de ese proceso ${ }^{9}$. La propia noción de Constitución no asume un lugar de destaque en el viejo continente, porque la misma trataba las relaciones públicas en pleno período de triunfo del privado. La relevancia estaba en el Código Civil y no en el texto constitucional. El Code era una especie de "Constitución de las relaciones privadas".

Con el transcurso del tiempo, la crisis de ese modelo liberal va a engendrar la necesidad de alteraciones en el papel del Estado y del Derecho, o sea que, del absentismo estatal liberal pasamos a la exigencia de la construcción de un modelo de Estado (y de Constitución, porque es imposible disociar esta de aquella) dotado de la capacidad de impedir la revolución que podría surgir de la incapacidad del liberalismo de generar una sociedad que compatibilizara progreso con distribución de renta y justicia social. Es este el escenario propio para el surgimiento del Estado de aspecto intervencionista, donde el polo de tensión del poder se desplaza en dirección al Ejecutivo. Al final, para realizar políticas públicas correctivas, era necesario un Estado fuerte y de un Derecho

9 Nace allí el debate que culminará en la creación, en el siglo xx, de los tribunales constitucionales. En efecto, no puede olvidarse que la exclusión del Poder Judicial —en territorio europeo- de la tarea de controlar la constitucionalidad de las leyes, tiene como fundamento antiguas tesis que llevaron a los revolucionarios franceses a la victoria final del siglo xviII. O sea, si la desconfianza en los jueces llevó la radicalización a Francia, donde el control es ejercido, aún hoy, por órganos políticos, esa misma desconfianza llevó, en otro nivel, a la exclusión de los jueces y/o tribunales ordinarios del control de constitucionalidad en la mayoría de los países europeos, mediante el establecimiento de Tribunales Constitucionales fuera de la estructura del Poder Judicial, históricamente carente de legitimidad. Los jueces americanos, por la especificidad en que ocurrió el proceso de independencia y la formación del Estado Nacional, no sufrieron el desgaste de los magistrados franceses. La decisión de Marshal de 1803 fue una decisión interventiva, «judicializadora de la polítican. Ese poder moderador de la US Supreme Court, que echa raíces en las ideas liberales de Benjamín Constant, ganó considerable relieve en la historia de los Estados Unidos y de los países latinoamericanos, en especial en Brasil, que adoptó la fórmula norteamericana ya en 1891. Sin embargo, frente a la experiencia francesa, esa "moderación" no podía ser llevada a cabo en Europa por el Poder Judicial. Había que buscar una tertio genus, que pudiera intervenir en las disputas entre los Poderes del Estado. Y nuevamente aquí asume relevancia el legado de la Revolución Francesa. En efecto, ese tertio genus no podría ser el Poder Judicial porque le faltaba legitimidad. No hay que olvidar, en este punto, que Europa continental —donde el poder legislativo históricamente tiene una posición prominente- posee una estructura judiciaria burocrática de base (magistrados de carrera), al contrario de los Estados Unidos que posee un sistema de base por elección, donde la separación de los Poderes es un dogma; el juez ocupa un lugar especial en el equilibrio constitucional, estableciendo el derecho no en base a principios abstractos como ocurre con el legislador, sino tratando concretamente las soluciones para los litigios (case law). En este punto el modelo brasileño sufre serios perjuicios porque es burocrático tanto en la base como en la cúpula, debido a la insistencia en mantener la tradición del control jurisdiccional heredado de los Estados Unidos desde la proclamación de la República. 
apto a albergar los actos promovedores necesarios de tales políticas (cf. por ejemplo, el embate entre el Poder Ejecutivo norteamericano y la suprema Corte, en ocasión del New Deal). Cambia el aspecto del Estado; se altera el aspecto del Derecho y de las Constituciones.

La segunda posguerra produce una tercera forma de Estado de Derecho ${ }^{10}$. La preocupación con los derechos fundamentales y la democracia engendra textos constitucionales que avanzan nítidamente en relación a los fundamentos del viejo liberalismo y a la noción puramente intervencionista del Estado Social.

La democracia y los derechos fundamentales pasan a ser el de los constitucionales que avanzan nítidamente en relación a los fundamentos del viejo liberalismo y a la noción puramente intervencionista del Estado Social. La democracia y los derechos fundamentales pasan a ser los dos sustentáculos de ese nuevo modelo, donde no puede haber retroceso. Por eso, para utilizar un lenguaje hermenéutico, es posible decir que la noción de Estado Democrático de Derecho que la tradición nos legó, es un existencial.

Cualquier problematización que se pretenda elaborar sobre la democracia y sobre la actuación de los agentes sociales tendrá lugar en ese espacio, donde ocurre el sentido del Derecho y de la democracia. El Estado Democrático de Derecho es, así, un "desde-ya-siempre", condicionador de nuestro actuar-en-elmundo, porque hace parte de nuestro modo de ser-en-el-mundo. El Estado Democrático de Derecho no es algo separado de nosotros. Él se manifiesta como un suceder. En este sentido, es posible decir que el actuar jurídico-político de los autores sociales encargados institucionalmente de hacer efectivas políticas públicas (lato sensu) tiene lugar en esa manifestación previa, donde ya existe un proceso de comprensión.

10 No es necesario recordar que la diferencia entre los conceptos de Estado Social y Estado Democrático y Social de Derecho no es controvertida. De acuerdo con el esquema propuesto por autores como Garronena (El Estado Español como Estado social y democrático de Derecho), la interpretación total o harmónica de esta fórmula de Estado puede ser presentada en un nivel duplo: 1) el de la interpretación recíproca de los términos de la fórmula aludida; y 2) el de la interpretación integral de la misma como proceso histórico dialéctico de diferentes tipos de Estados. De acuerdo con la idea de interpretación integral, este Estado se coloca dentro de un lugar determinado de un proceso histórico. Se parte, para ello, de la aceptación de la entidad dialéctica, histórica, de la institución estatal, progresivamente alterada en sus aspectos esenciales en virtud de un proceso que iría del Estado policial al Estado de Derecho, para, después del período de las revoluciones burguesas y el inicio del constitucionalismo moderno de una serie de autocorrecciones del Estado liberal burgués, que, finalmente, con el desarrollo del Estado Social de Bienestar, tendrá que corregir las contradicciones económicas del modelo anterior, pretendiendo incluso la superación del neocapitalimo. Algunos sectores de la doctrina entienden que, para llegar a la etapa final -integral- el Estado Democrático de Derecho tiene que adoptar una estructura económico-social. Por esto Elías DÍAZ, en su Estado de Derecho y Sociedad Democrática dice que el Estado Democrático de Derecho aparece como superación real del Estado social de Derecho. Ver CONDE, Enrique Álvarez, Curso de Derecho Constitucional. Madrid, Tecnos, 1996, pp. 108 y sig. A partir de esto, es posible decir que el Estado Social de Derecho y el Estado Democrático de Derecho son fases sucesivas en el proceso de transformación del Estado Contemporáneo, el primero respondiendo a los esquemas de superación de la crisis del liberalismo y el segundo tratando la inserción en aquello que se puede denominar de socialismo democrático, tesis defendida por Días. 
Es en ese contexto en el que se asienta la legitimidad de la justicia constitucional en el cuadro del Estado Democrático de Derecho, es decir, ella no está solamente en la especificidad propia de los tribunales ad hoc, sino en la existencialidad (en el sentido hermenéutico que adopto) de los pilares que fundamentan esa misma noción. De aquí se puede concluir que, mientras sea existencial, el Estado Democrático de Derecho fundamenta anticipadamente (círculo bermenéutico), la legitimidad de un órgano estatal que tiene la función de resguardar los fundamentos (derechos sociales-fundamentales y democracia) de ese modelo de Estado de Derecho. El carácter existencial del Estado Democrático de Derecho pasa a ser la condición de posibilidad del actuar legítimo de una instancia encargada, incluso —en su límite- de viabilizar políticas públicas resultantes de inconstitucionalidades por omisión, constituyéndose en remedio, a veces amargo, pero necesario, contra la actuación de mayorías (eventuales o no).

Por ello, cuando preguntamos por la legitimidad de ese actuar de la justicia constitucional, la respuesta ya encontró "guarida" — desde hace mucho tiempo- en el carácter existencial del Estado Democrático de Derecho, fulcrado en el modelo-de-ser propio de las democracias engendradas por la tradición de la segunda posguerra.

\section{CONSTITUCIÓN, DERECHO Y DEMOCRACIA: LAS DIMENSIONES PROCESALES Y SUBSTANTIVAS-UN DEBATE NECESARIO}

La discusión de estas cuestiones, evidentemente, presupone algunas comprensiones previas, a saber: si se está hablando/indagando sobre la función de la jurisdicción constitucional en la concretización de derechos sociales-fundamentales, es porque se está admitiendo que, primero, hay un grado de inefectividad de la Constitución, y segundo, habiendo inercia de los Poderes Públicos en la realización/implementación de políticas públicas aptas a la efectivación de los derechos sociales-fundamentales asegurados por la Constitución, es posible (y necesaria) la intervención de la justicia constitucional. Obviamente, tales cuestiones implican otras tres, que se interpenetran: a) la necesidad de una redefinición en la relación entre los Poderes del Estado; b) la admisión de que la justicia constitucional pueda tener un papel intervencionista, y c) un cierto grado de dirigismo constitucional. Por otro lado, parece no haber dudas de que, sosteniendo esa discusión, esta concepción de Estado Democrático de Derecho ${ }^{11}$ está vinculada inexorablemente a la función transformadora que el Derecho asume. De la idea de Derecho como ordenación e incluso como promoción, surge un papel para el Derecho que va mucho más lejos que la Constitución como mero instrumento para la aferición de la parametricidad formal. Esto demandó un nuevo tipo de concepción acerca de la

11 Para una explicación más detallada, ver STRECK, Lenio Luiz. Jurisdição Constitucional e Hermenêutica-Uma Nova Crítica do Direito. Rio de Janeiro, Forense, 2003 
jurisdicción constitucional. Se trata de la institución de tribunales (constitucionales) aptos para instrumentalizar y proteger la materialidad de los textos constitucionales.

En este sentido, ante las profundas alteraciones paradigmáticas ocurridas en la teoría del Estado y de la Constitución, la noción de Estado Democrático de Derecho presupone una valorización de lo jurídico, y, fundamentalmente, exige la (re)discusión del papel destinado a la justicia constitucional en ese (nuevo) panorama establecido por el constitucionalismo de la segunda posguerra, especialmente en países como Brasil, cuyo proceso constituyente de 1986-88 asumió una posición que Cittadino ${ }^{12}$ muy apropiadamente denominada "comunitarista", donde los constitucionalistas (comunitaristas) lucharon por la incorporación de los compromisos ético-comunitarios en la Constitución, tratando no solo de reconstruir el Estado de Derecho, sino también de srescatar la fuerza del Derecho", cometiendo la jurisdicción a la tarea de guardiana de los valores materiales positivados en la Constitución.

La noción de Estado Democrático de Derecho está indisociablemente ligada a la realización de los derechos fundamentales-sociales. Es de esa unión indisoluble que surge aquello que se puede denominar de plus normativo del Estado Democrático de Derecho. Más que una clasificación o forma de Estado o de una variante de su evolución histórica, el Estado Democrático de Derecho hace una sintesis de las fases anteriores, agregando la construcción de las condiciones de posibilidades para suplir las lagunas de las etapas anteriores, representadas por la necesidad del rescate de las promesas de la modernidad ${ }^{13}$, tales como igualdad, justicia social y garantía de los derechos bumanos fundamentales.

A esa noción de Estado se acopla el contenido material de las constituciones, a través de los valores substantivos que apuntan hacia un cambio del status quo de la sociedad. Por eso, en el Estado Democrático de Derecho la ley (Constitución) pasa a ser una forma privilegiada de instrumentalizar la acción del Estado en la búsqueda del desiderátum señalado por el texto constitucional, entendido en su todo dirigente-compromisario-valorativo-principiológico.

La democratización social, fruto de las políticas del Welfare State, el advenimiento de la democracia en la segunda posguerra y la redemocratización de países que salieron de regímenes autoritarios/dictatoriales, traen a la luz Constituciones cuyos textos positivan los derechos fundamentales y sociales. Ese conjunto de factores va a rediseñar, necesariamente, la relación entre los Poderes del Estado, pasando el Poder Judicial (o los tribunales constitucionales) a hacer parte de la arena política, esto porque el Welfare State le facultó el acceso a la administración del futuro, y el constitucionalismo moderno, a partir de la ex-

12 Cfe. CITTADINO, Gisele. Pluralismo, Direito e Justiça Distributiva. Elementos da Filosofia Constitucional Contemporânea. Río de Janeiro, Lúmen Júris, 1999, p. 226 y sig.

13 Sobre las así denominadas "promesas de la modernidad", ver STRECK, Jurisdição, op.cit., cap. 1 a 5 . 
periencia negativa de legitimación del nazi-fascismo por la voluntad de la mayoría, confió a la justicia constitucional la custodia de la voluntad general, encerrada de modo permanente en los principios fundamentales positivados en el orden jurídico. Tales factores provocan un redimensionamiento en la clásica relación entre los Poderes del Estado, surgiendo el Judiciario (y sus variantes de justicia constitucional, en los países que adoptaron la fórmula de tribunales ad hoc) como una alternativa para el rescate de las promesas de la modernidad, donde el acceso a la justicia asume un papel de fundamental importancia, a través del desplazamiento de la esfera de acción, hasta entonces calcada de los procedimientos políticos a los procedimientos judiciales ${ }^{14}$.

De este modo, en la medida en que la Constitución asume un carácter primordial en esa arena política, a partir de esa revolución copernicana de la que habla Jorge Miranda, representada por el advenimiento del Estado Democrático de Derecho, inexorablemente nos plantearemos las siguientes preguntas: ¿¿cuál es la relación entre el derecho y la política? ¿En qué medida el Derecho, establecido en el texto constitucional, puede establecer "el estatuto jurídico de lo político? ¿Y cuál es la dimensión del Derecho que debe ser privilegiada? ¿En qué medida el Derecho, establecido en el texto constitucional puede establecer "el constituir" de la Sociedad? ¿En qué medida la Constitución es o puede continuar siendo el estatuto jurídico de lo político? ¿Y cuál es la dimensión del Derecho que debe ser privilegiada? ¿La procesal o la substantiva?

\section{II.1. El PROCEDIMENTALISMO Y LA CRÍTICA AL "ACTIVISMO JUDICIAL"}

Muy a pesar de que procedimentalistas y substancialistas ${ }^{15}$ reconozcan en el Poder Judicial y, en especial, en la justicia constitucional, una función estratégica en las Constituciones de la segunda posguerra, la corriente procedimentalista, capitaneada por autores como Habermas, Garapon y Ely, presenta considerables divergencias ${ }^{16}$ con la corriente substancialista, apoyada por autores como Mauro Cappelletti, Bruce Ackerman, L.H. Tribe, M.J. Perry ${ }^{17}$, H.H. Wellington $^{18}$, en cierta medida por Dworkin, por lo menos en la lectura que de

14 Consultar VIANNA, Luiz Werneck; CARVALHO, Maria Alice Rezende de. CUNHA MELO, Manuel Palácios; Burgos, Marcelo Baumann. A judicialização da política e das relações sociais no Brasil. Río de Janeiro, Editora Revan, p. 22 e 23.

15 La división entre dos ejes analíticos (procedimentalismo y substancialismo) es propuesto por Vianna, op.cit.

16 Para una crítica de los valores substantivos y del activismo judicial, ver STARCK, Christian. La legitimité de la justice constitutionnelle et le principe democratique de majorité. In: Legitimidade e legitimação da justiça constitucional. Coimbra, Coimbra Editores, 1995, p. 59 y sig.

17 De este autor, ver The Constitution, the Courts and Human Rights. An Inquiry into the Legitimacy of Constitutional Policymaking by the Judiciary. Yale University Press, New Haven and London, 1982.

18 La posición de Wellington está en Common Law Rules and Constitutional Double Standards: Some Notes on Adjudication. The Yale Law Journal, vol. 83, n. 2, diciembre 1973. 
él hace Robert Alexy, y en Brasil por juristas como Paulo Bonavides y Eros Roberto Grau, entre otros.

Apoyando la tesis procedimentalista, Habermas ${ }^{19}$ critica con vehemencia la invasión de la política y de la sociedad por el Derecho. El paradigma procedimentalista pretende superar la oposición entre los paradigmas liberal/formal/burgués y el del Estado Social de Derecho, valiéndose para ello, de la interpretación de la distinción entre política y derecho a la luz de la teoría del discurso. Parte de la idea de que los sistemas jurídicos surgidos al final del siglo xx, en las democracias de masas de los Estados Sociales, denotan una comprensión procedimentalista del Derecho. Así, en el Estado Democrático de Derecho, a pesar de que Habermas reconoce la importancia de la tarea política de la legislación como tamiz de universalidad en lo que se refiere a aceptabilidad generalizada - tamiz por el que tienen que pasar las normas a ser genérica y abstractamente adoptadas - ve en lo Judicial el centro del sistema jurídico, mediante la distinción entre discursos de justificación y discursos de aplicación a través de la cual resalta al máximo el postulado de Ronald Dworkin de la exigencia de imparcialidad no solamente del ejecutivo, sino, sobretodo, del juez en la aplicación y definición cotidiana del Derecho.

Habermas presenta severas críticas a la lectura substancialista que Alexy hace del modelo constructivo del Derecho de Dworkin y, aunque a partir de otras bases, siguiendo a W. Böckenfoerd a aquello que denomina gigantismo o politización del poder judicial, surgido en la segunda posguerra ${ }^{20}$. La existencia de tribunales constitucionales no es autoevidente para Habermas. Y aún donde ellos existen — el autor se restringe a Alemania y a los Estados Unidos- hay controversias sobre su lugar en la estructura de competencias del orden constitucional y sobre la legitimidad de sus decisiones. Critica, así, la idea de concretización de los valores materiales constitucionales, aludiendo que, "al dejarse conducir por la idea de la realización de valores materiales, dados preliminarmente en el derecho constitucional, el tribunal constitucional se transforma en una instancia autoritaria”. La invasión de la esfera de competencia de los tribunales, mediante concretizaciones materiales de valores, desestimula el actuar orientado hacia fines cívicos, transformándose en juez y la ley en las últimas referencias de esperanza para individuos aislados ${ }^{21}$. Aun más, Habermas hace una crítica a la jurisdificación propia del modelo del Estado Social llamándola de "colonización del mundo de la vida ${ }^{22}$."

Ante esto, Habermas propone un modelo de democracia constitucional que no tiene como condición previa fundamentarse ni en valores compartidos, ni en contenidos substantivos, sino en procedimientos que aseguran la for-

19 Consultar HABERMAS, Jürgen. Direito e democracia-entre facticidade e validade, I e II. Río de Janeiro, Tempo Brasileiro, 1997, especialmente p. 297 y sig. (I) e 170 y sig. (II)

20 Cfe. HABERMAS, Direito e Democracia-entre facticidade e validade. I, op.cit., en especial, p. 245 y sig.

21 Ídem, ibídem.

22 Ver el análisis agudo de NEVES, Marcelo. Entre Têmis e Leviatã: uma relação difícil. São Paulo, USP, 1997, p. 142, 275 y 276. 
mación democrática de la opinión y de la voluntad y que exige una identidad política no más anclada en una "nación de cultura"sino en una "nación de ciudadanos". Critica la así denominada "jurisprudencia de valores" adoptada por las cortes europeas, especialmente la alemana. Una interpretación constitucional orientada por valores que opta por el sentido teleológico de las normas y principios constitucionales, ignorando el carácter vinculante del sistema de derechos constitucionalmente asegurados, desconoce, en la opinión de Habermas, no exclusivamente el pluralismo de las democracias contemporáneas, sino fundamentalmente la lógica del poder económico y del poder administrativo. La concepción de comunidad ética de valores compartidos, que justifica el modelo hermenéutico propuesto por los comunitarios (o substancialistas) ${ }^{23}$, parece desconocer las relaciones de poder asimétricas inscriptas en las democracias contemporáneas ${ }^{24}$. Con relación a la función de la justicia constitucional, Habermas sustenta que el Tribunal Constitucional debe quedar limitado a la tarea de comprensión procedimental de la Constitución, es decir, limitándose a proteger un proceso de creación democrática del Derecho. Para el autor, el Tribunal Constitucional no debe ser un guardián de un supuesto orden suprapositivo de valores substanciales. Debe, sí, celar a fin de garantizar que la ciudadanía disponga de medios para establecer un entendimiento sobre la naturaleza de sus problemas y la forma de una solución ${ }^{25}$.

En el mismo diapasón, Antoine Garapon hace duras críticas a la invasión de la sociedad por el poder judicial, lo que, según el autor, serviría para el debilitamiento de la democracia representativa ${ }^{26}$. También J.H. Ely comparte el paradigma procedimentalista, sosteniendo que el tribunal constitucional solo puede conservar su imparcialidad si resiste a la tentación de llenar su espacio de interpretación con juicios de valores morales. No está de acuerdo con la jurisprudencia de valores ni tampoco con una interpretación dirigida por principios, en el sentido de la interpretación constructiva de Dworkin ${ }^{27}$.

\section{II.2. Porqué Debemos OPONER RESTRICCIONES A LAS TESIS PROCEDIMENTALISTAS}

Por varias razones debe ser criticada la concepción procedimentalista. De esta manera cuando Habermas opone el paradigma del derecho liberal/formal burgués al paradigma del derecho del bienestar (Estado Social), diciendo que

23 Cfe. HABERMAS, Direito e Democracia I, op. cit.

24 Cfe. HABERMAS, Jürgen. Direito e Democracia II, op. cit., p. 170 y sig.; ídem, Más Allá del Estado Nacional. Madrid, Ed. Trotta, 1997, p. 99 y sig.; tb. Citadino, op. cit., p.212; Vianna et al, op. cit.

25 Cfe. HABERMAS, Direito e Democracia I, p. 297 e segs. e II, p. 170 e segs. tb. Más Allá Del Estado Nacional, op. cit., p. 99 y sig.

26 Ídem, ibídem; tb. Garapón, Antoine. Le Gardien de Promesses. París, Odile Jacob, 1996; especialmente Vianna, et al, op. cit.

27 Cfe. HABERMAS, Direito e Democracia, op. cit., p. 328. Tb. Ely, J. H. Democracy and Distrust. A theory of Judicial Review. Cambridge/Mass, 1980, p.133. 
ambos están superados, deja de reconocer la existencia de un tercer paradigma, que es el modelo del Estado Democrático de Derecho y, con esto, corre el riesgo de cosificar la Constitución. En efecto, su análisis subestima el Derecho en lo que es su plus normativo que quedó caracterizado exactamente en el constitucionalismo de la segunda posguerra, en la fórmula instituida en y por el Estado Democrático de Derecho, que supera las nociones anteriores de Estado Liberal y Estado Social de Derecho; no obstante, no reconoce la diferenciación necesaria que existe entre el modelo del Estado Social de Derecho y el modelo del Estado Democrático de Derecho, que, insisto, supera la noción de Estado Social. Y ahí empieza el problema...

O sea, de algún modo, Habermas cae en un cierto sociologismo al ignorar la especificidad de lo jurídico presente en las Constituciones, que generó todo un proceso de revitalización del poder judicial, en lo que concierne a la función social del Derecho. El constitucionalismo del Estado Democrático de Derecho acrecienta un "más" al Derecho del Estado Social, porque establece en el propio texto constitucional - $-\mathrm{y}$ ese es el punto que Habermas deja de considerar- los diversos mecanismos para el rescate de las promesas de la modernidad. Lo que diferencia el proyecto del Estado Democrático de Derecho es exactamente la revalorización del Poder Judicial, como contrapunto a la plenipotenciariedad de la razón política que tantas secuelas dejó. Como bien señala, el Estado Democrático de Derecho aparece como superación real del Estado Social de Derecho $^{28}$.

Así, mientras el modelo de Derecho del Estado Social es resultante de una crítica reformista del paradigma del derecho liberal $-\mathrm{y}$ en esto Habermas tiene plena razón-, el modelo de Derecho del Estado Democrático de Derecho sobrepasa ambas concepciones. En la misma línea, si es verdad que los dos paradigmas están anclados en un mismo concepto de autonomía privada, Habermas no lleva debidamente en cuenta la circunstancia relevante de que el paradigma del Estado Democrático de Derecho se ancora en un modelo en el que la resultante social que se establece a partir de la noción de ciudadanía adviene de una intersubjetividad, en que la relación sujeto-sujeto sobrepasa la relación extemporánea sujeto-objeto, superando el monadismo típico del paradigma de la autoconsciencia.

El Estado Democrático de Derecho es un nuevo paradigma porque fue engendrada una nueva legitimidad en el campo del derecho constitucional y de la ciencia política, en el interior de la cual el Derecho asume la tarea de transformación, e incluso ante la crisis del modelo de Estado Social donde las políticas públicas empezaron a hacerse escasas, cuestión que ponía en riesgo la realización de los derechos sociales y fundamentales. De ahí que se altere la configuración del proceso de legitimación: al contrario de las constituciones liberales o meramente sociales, la legitimidad, ahora, adviene de la propia Constitución (Villalón), que emana de un proceso de refundación de la sociedad.

Aún más, es necesario tener en cuenta que el paradigma del Estado Social-

28 Ver DÍAZ, op.cit., Estado de Derecho, op. cit., p.134. 
Intervencionista trabaja con la perspectiva de un Estado que interviene a través de políticas que no son $-\mathrm{O}$ raramente son- elecciones motivadas por un querer genético de la sociedad, reflejando, antes que nada, los intereses de los grupos eventualmente en el poder ${ }^{29}$. Por ello, el advenimiento del Estado Democrático de Derecho representa un salto y un plus (normativo) sobre el modelo anterior de Estado-intervencionista, principalmente si consideramos - como se vio antes - las especificidades brasileñas. Se trata, en fin, de entender que el Estado Democrático de Derecho surge de una nuevo pacto, con las especificidades propias de cada país. En este contexto, la noción de Estado Democrático de Derecho aparece como superador de la noción de Estado Social. O sea, la noción de Estado Social dependía de mecanismos implementadores, razón por la cual el Derecho apareció (en los textos constitucionales) con una faz transformadora.

Así, si en el paradigma liberal el Derecho tenía la función meramente ordenadora, estando en la legislación el punto de tensión en las relaciones entre Estado-Sociedad, en el Estado Social su función pasa a ser promovedora, estando indicadas las baterías para el Poder Ejecutivo, por la razón exacta de la necesidad de realización de las políticas del Welfare State. Ya en el Estado Democrático de Derecho, fórmula constitucionalizada en los textos magnos de las principales democracias, la función del Derecho se hace transformadora, donde el polo de tensión, en determinadas circunstancias previstas en los textos constitucionales, pasa para el Poder Judicial o los Tribunales Constitucionales.

Entonces, la libertad de conformación del legislador, pródiga en discrecionalidad en el Estado-Liberal, es contestada por dos lados: por un lado, los textos constitucionales dirigentes (la tesis original de Constitución dirigente Dirigierende Verfassung — es de Peter Lerche, radicalizada por J. Gomes Canotilho, en su Constitución Dirigente y Vinculación del legislador), apuntando para un deber de legislar en pro de los derechos fundamentales y sociales; por otro lado, el control por parte de los tribunales, que pasaron no solamente a decidir sobre la forma procedimental de la acción de las leyes, sino sobre su contenido material, incorporando los valores previstos en la Constitución. De allí surgen los siguientes interrogantes: ¿Cómo tener ciudadanos plenamente autónomos, como Habermas propugna, si el problema de la exclusión social no ha sido resuelto? ¿Cómo tener ciudadanos plenamente autónomos si sus relaciones están colonizadas por la tradición que les conforma el mundo de la vida? En este sentido, apoyado en Ackerman ${ }^{30}$, pregunto: ¿Puede una elección ser libre y justa si una gran parte del electorado carece de instrucción necesaria para comprender las principales líneas del debate político? ¿O si están pasando

29 Ese diagnóstico está muy bien explicitado por Luciano DE OLIVEIRA y Alonso PEREIRA APUD GRAU, Eros ROBERTO. A Ordem Econômica na Constituição de 1988. Interpretação e Crítica. 2. ${ }^{\text {a }}$ ed. San Pablo, RT, 1991, p. 148-149.

30 Cfe. ACKERMAN, Bruce. La politica del diálogo liberal. Barcelona, Gedisa, 1999, p. 148 e 149 . 
hambre o trabajando en condiciones opresivas durante la mayor parte de su tiempo? "Mi respuesta es no", va a decir Ackerman. Si usted está de acuerdo, este primer fundamento le permite preparar un camino conceptual para considerar hasta dónde los jueces deberían estar facultados constitucionalmente para intervenir también en estos asuntos. Por consiguiente, la concesión de una facultad semejante puede verse limitada por toda suerte de consideraciones. No obstante, lo que interesa aquí, acentúa el profesor norteamericano, son los principios básicos: al habilitar a los jueces para insistir en un piso democrático" en la evaluación de medidas de bienestar y educacionales propuestas por los gobernantes, no si está abogando la "muerte del político" sino por su reorganización y extensión, que debe abarcar desde un interés por el centro de decisiones hasta la protección de la vida política que se experimenta en la periferia.

En el fondo, cuando Habermas presenta su tesis del sujeto autónomo, se coloca del lado de la realidad, poniéndola entre paréntesis, aunque no la sigue. Como Husserl, Habermas no ve la realidad como una construcción ontológica, sino como necesidad de ser recuperada a través de la descripción de los actos conscientes, de la conciencia trascendental. En este sentido, el lugar de la autonomía nacería de un como (wie) de los fenómenos sociales. Ese como (wie) asume una característica epistemológica, donde el procedimiento es el medio para alcanzar esa autonomía del sujeto ${ }^{31}$.

Trabajando el texto constitucional exclusivamente en su aspecto procedimental, se abre espacio para el oscurecimiento (en el sentido hermenéutico) ${ }^{32}$ de aquello que la Constitución es en el sentido negativo: los derechos sociales no realizados, los derechos fundamentales no respetados. Además, se corre siempre el riesgo de entender el Derecho - en lo que atañe a los valores substantivos constitucionales - como un mecanismo (meramente) reductor de complejidades (sistemismo luhmanniano), impidiendo que aparezca el sentido transformador propio del paradigma del Estado Democrático de Derecho. Finalmente, se corre el riesgo de transformar el Derecho Constitucional en un Derecho Constitucional simbólico, frustrando las expectativas emanentes del contrato social, entendido aquí, de acuerdo a lo que ya se vio, a partir de un paradigma hermenéutico.

Todavía hay que considerar otro problema: Habermas parece menospreciar la vaguedad y la ambigüedad inherentes a los textos jurídicos (iincluso los que tratan de los procedimientos!). Además, como Villalón indaga sutilmente: "¿Cuál es la parte que corresponde al legislador y cuál es la parte que corresponde al juez constitucional?, Al condenar el activismo del Poder Judicial (o de la Justicia Constitucional), el maestro alemán relega para un segundo plano las normas (textos) que contemplan los valores constitucionales, con lo

31 Esa crítica a Habermas tomo prestada de Ernildo Stein, en su Seminário sobre a verdade (Petrópolis, Vozes, 1983), parte final, debiendo, naturalmente, ser contextualizada en los límites de estas reflexiones.

32 Sobre la concepción de hermenéutica aquí trabajada, ver STRECK, Lenio Luiz. Hermenêutica Jurídica E(m) Crise. Uma exploração hermenêutica da construção do Direito. 4a . Porto Alegre, Livraria do Advogado, 2003. 
que, como ya fue dicho, incurre en la separación entre ser y ente, cuya consecuencia es el oscurecimiento de la cuestión que es clave en la hermenéuti$\mathrm{ca}^{33}$ : la de que hermenéutica es aplicación (applicatio), que tiene lugar a partir del círculo hermenéutico, donde hay una anticipación de sentido. No bay proceso bermenéutico sin aplicación, punto fundamental en la separación entre el modelo clásico de la hermenéutica y la hermenéutica filosófica. La comprensión, condición de posibilidad para la interpretación, presupone una anticipación de sentido, la integración de la parte que debe ser comprendida en un conjunto preconcebido. La comprensión es así, un proceso de aproximación en desarrollo. Este proceso se desenvuelve en el tiempo, poniendo en juego al individuo con su historia vital y el contexto de las tradiciones sociales (precomprensión).

Por último, cabe destacar que el procedimentalismo habermasiano parece olvidarse que, en aquello que la tradición ha entendido como Derecho, la coerción es el elemento fundamental del proceso que somete a los individuos en el interior de cada Estado. El mandato para el ejercicio de la coerción es propio del Estado que lo ejerce a partir de sus instituciones. Como consecuencia, ocurre inexorablemente un proceso de supresión de la autonomía de los individuos en sociedad, porque la salvaguardia es introducida coercitivamente. Habermas, a su vez, pretende una salvaguardia que no es de orden jurídico, sino de orden social; una salvaguardia instaurada por la propia sociedad, lo que implica en una autonomía de la sociedad ante el Derecho, donde la legitimación se produce desde un espacio de índole social-comunicativa, y no socialcoercitiva. Por eso, el papel del Derecho (y de los Tribunales) queda relegado a la tarea de abrir (y garantizar) un espacio público, donde, en síntesis, es la sociedad civil la que funda el Derecho.

\section{II.3. El SUBSTANCIALISMO Y LAS CRÍTICAS NECESARIAS A LAS TESIS PROCEDIMENTALISTAS}

Como contrapunto a las tesis procedimentalistas, Cappelletti desde hace mucho tiempo sostenía que el Poder judicial puede contribuir para el aumento de la capacidad de incorporación del sistema político, garantizando a grupos marginales, destituidos de los medios para acceder a los poderes politicos, una oportunidad para la vocalización de sus expectativas y derecho en el proceso judicial. Aunque clasificable como defensor de una posición liberal-contractualista, Dworkin ${ }^{34}$ se aproxima, en algunos puntos, a esa posición, enten-

33 Ídem, ibídem.

34 Evidentemente, las tesis dworkianas, en determinados aspectos, no pueden escapar a las críticas. La delegación en favor del juez para apoyarse en sí mismo a partir de una especie de privilegio cognitivo - la idea del juez Hércules - así como la tesis de que siempre hay una única decisión correcta no se coadunan con el pensamiento posmetafísico, i.e. con el viraje lingüístico. 
diendo que la creación jurisprudencial del derecho también encontraría su fundamento en la primacía de la Constitución ${ }^{35}$. Véase la tesis de L.H. Tribe, uno de los más férreos defensores de los valores substantivos constitucionales y de estos en cuanto guía del proceso hermenéutico-constitucional.

Para eso, hace una profunda crítica a las bases de las teorías de los valores adjetivos o procedimentalistas, para las cuales Constitución solamente garantiza el acceso a los mecanismos de participación democrática en el sistema. En este sentido, afirma que el procedimiento debe completarse con una teoría de los derechos y valores substantivos. Parte del carácter tenazmente substantivo (stubbornly substantive character) de la mayoría de los mandatos constitucionales más importantes: la primera enmienda, la decimotercera (abolición de la esclavitud) o la cláusula del debido proceso legal son buenos ejemplos de esto. Por otro lado, también son substantivos el significado y el propósito de las normas que regulan los procedimientos de participación. Seguramente, dice Tribe, decidir qué clase de participación demanda la Constitución requiere una teoría de los valores y de los derechos plenamente substantiva. Así, los derechos al procedimiento del debido proceso conlleva en su base la dignidad personal (ser escuchado y parte de lo que significa ser persona); del mismo modo, la cuestión de "quién vota" o la regla "un hombre, un voto" poseen carácter substantivo. Las teorias procedimentalistas no parecen apreciar que el proceso es algo en sí mismo valioso; no obstante, decir que el proceso es en sí mismo valioso es afirmar que la Constitución es inevitablemente substantiva ${ }^{36}$.

Aún más, Tribe dice que la protección de las minorías aisladas y sin voz, excluidas del proceso de participación política, poseen también un fundamento substantivo: la legislación que discrimina a cualquier categoría de personas debe ser rechazada en base a una idea sobre lo que significa ser persona, y la propia idea de segregación de los negros o mujeres solamente puede ser rechazada encontrando una base constitucional para afirmar que, en nuestra sociedad, tales ideas están substantivamente fuera de lugar. En síntesis, para Tribe, circunscribir la interpretación constitucional a la idea de abertura política supone un círculo vicioso. Por eso, las teorías defensoras de la Constitución como proceso (como garantía de abertura y de participación) suponen un empobrecimiento del papel de la teoría constitucional: la Constitución parecería estar dirigida solamente a los jueces y no a los ciudadanos ni a los representantes, en vista de su incapacidad para informar en el contenido del debate, discusión y decisión política ${ }^{37}$.

35 Consultar CAPPELLETTI, Mauro. Juizes Legisladores? Porto Alegre, Fabris, 1988; Dworkin, Ronald. L'empire du Droit. París, PUF, 1994; ídem Taking Rights Seriously. Cambridge, Harvard University Press, 1977; Vianna et al, op. cit.

36 Consultar TRIBE, L. H. The Puzzling Persistence of Process-Based Constitutional Theories, In: The Yale Law Journal, vol. 89, 1073, 1980, p. 1065 y sig.; Ibídem, American Constitutional Law. The Foundation Press, Mineola, New York, 2a. ed., 1988; Ibídem Taking Text and Structure Seriously: reflection on free-form method in constitutional interpretation, In: Harvard Law Review, vol. 108, n. 6, 1995. Véase también, DÍAZ REVORIO, Francisco Javier. La Constitución como orden abierto. Madrid, Estudios Ciencias Jurídicas, 1997.op. cit., p. 161 y sig.

37 Ídem, ibídem. 
En síntesis, la corriente substancialista entiende que, más que equilibrar y armonizar los demás poderes, el poder judicial debería asumir el papel de un intérprete que pone en evidencia, incluso contra mayorías eventuales, la voluntad general implícita en el derecho positivo, especialmente en los textos constitucionales, y en los principios seleccionados como de valor permanente en su cultura de origen y en la del Occidente ${ }^{38}$. Pone en jaque, por lo tanto, el principio de la mayoría en favor de la mayoría fundante y constituyente de la comunidad política.

El modelo substancialista —que, en parte, aquí suscribo, salvando siempre el problema del "fundamento" de la Constitución ${ }^{39}$ que no puede ser entendida como una categoría o hipótesis, sino y ante todo, como una paradoja, trabaja en la perspectiva de que la Constitución establece las condiciones del actuar político-estatal, a partir del presupuesto de que la Constitución es la explicitación del contrato social (contrato social también debe ser entendido a partir del paradigma hermenéutico y no como un punto de partida congelado). Es el constitucionalismo-dirigente que ingresa en los ordenamientos de los países después de la segunda guerra. Consecuentemente, es inexorable que, con la positivación de los derechos sociales-fundamentales, el poder judicial (y, en especial, la justicia constitucional) llegue a tener un papel de absoluta relevancia, principalmente en lo que concierne a la jurisdicción constitucional.

Los abordajes que, de un modo o de otro, trabajan con ese enfoque, parten de la perspectiva de que la función de la jurisdicción constitucional debe hacer prevalecer la Constitución contra las mayorías eventuales. Cabe subrayar, aquí, lo manifestado por Korineck ${ }^{40}$, para quien la vinculación del legislador a las determinaciones constitucionales es al mismo tiempo la vinculación del legislador democráticamente legitimado a un acto de la más elevada legitimación democrática.

Ese es el concepto clave del Estado Social, cuyo papel «es el de promover la integración de la sociedad nacional, o sea, "el proceso constantemente renovado de conversión de una pluralidad en una unidad sin perjui-

38 Cfe. VIANNA, op. cit.

39 Sobre la cuestión del fundamento, consultar Jurisdição Constitucional e Hermenêutica, op.cit, cap. 5, donde están explicadas las bases de lo que denomino una Nueva Crítica del Derecho $(N C D)$, de carácter antimetafísico, donde trato de superar el equívoco de las teorías tradicionales sobre la interpretación las que, a pesar de que reconozcan que el Derecho se caracteriza por un proceso de aplicación (concretud), permanecen rehenes del paradigma metafísico, en la medida en que elaboran un proceso de subsunción a partir de significantes-primordiales-fundantes (en sus variadas formas, ya sea a partir de un topos de la tópica retórica, o del sistema de normas propuesto por la interpretación sistemática, o incluso a partir de la subdivisión en sintaxis, semántica y pragmática de la semiótica tradicional), que será "acoplado" a un caso. La Nueva Crítica del Derecho (NCD) procura también superar viejos dogmas que sustentan las teorías sobre la interpretación del Derecho, como el del proceso hermenéutico dependiente de un método o de metacriterios para comprobación de la verdad.

40 Cfe. KORINECK. Die Verfassugnsgerichtsbarkei im Gefüge der Staatsfunktionen. VVDStRL, Berlín, 1981, p. 45 e 46. 
cio de la capacidad de autodeterminación de las partes" (Manuel García Pelayo $)^{41}$.

De este modo, la noción de Constitución que se pretende preservar en esta etapa de la historia es aquella que contenga una fuerza normativa capaz de asegurar ese núcleo de modernidad tardía no cumplida. Ese núcleo se consubstancia en los fines del Estado Social establecidos en las Constituciones de perfil transformador. La atención a esos fines sociales y económicos es condición de posibilidad de la propia inserción del Estado Nacional —o de lo que de él aún resta- en el campo de la posmodernidad globalizante. Cuando - para desconcierto de muchos constitucionalistas - continúo apostando en un "dirigismo" constitucional, no estoy hablando de un concepto desvinculado de la contemporaneidad que cerca la noción de Estado nacional ni tampoco pretendo un aislamiento de cuño monádico-autárquico (utilizando la expresión de Gomes Canotilho, "un autismo nacionalista e patriótico")

En verdad, lo que propongo es que los mecanismos constitucionales puestos a disposición del ciudadano y de las instituciones sean utilizados, eficazmente, como instrumentos aptos para evitar que los poderes públicos dispongan libremente de la Constitución. La fuerza normativa de la Constitución no puede significar la opción del cumplimiento ad hoc de dispositivos "menos significativos" de la Ley Mayor y el incumplimiento sistemático de lo que es más importante su núcleo esencial-fundamental. ¡Es lo mínimo que se puede exigir!

Dicho de otra manera, no cumplir con los dispositivos que consubstancian el núcleo básico de la Constitución, es decir, aquellos que establecen los fines del Estado (lo cual implica trabajar con la noción de "medios" aptos para la consecución de los fines), representa solapar el propio contrato social (del cual la Constitución es el eslabón de contenido que vincula lo político y lo jurídico de la sociedad). El texto constitucional, fruto de ese proceso de repactuación social, no puede ser transformado en un latifundio improductivo. No puede ser deslegitimado. Al final, como bien señala Friedrich Müller, la función del derecho constitucional, de la legislación y de la concretización de la Constitución es exactamente la de mantener la legitimidad del agrupamiento políticoestatal.

Por otra parte, defender la fuerza normativa de la Constitución no significa elevar la Constitución a la condición de texto sagrado. Añado, además, que el texto constitucional también no puede ser comprendido "como" (als) categoría o hipótesis, lo que igualmente sería deslizar hacia la metafísica. Hermenéuticamente, todo texto es un texto abierto, lo que no pasa incólume por el río de la historia...En síntesis, si los derechos sociales-fundamentales constituyen la "esencia" de la Constitución, parece razonable afirmar que la idea de la programaticidad de la Constitución debe ser mantenida, por la simple razón de que, sin la perspectiva dirigente-compromisaria, resulta imposible llevar a cabo los derechos que hacen parte de la esencia de la Constitución.

41 Cfe. BERCOVICI, Gilberto. Constituição e superação das desigualdades regionais. In: $D i$ reito Constitucional —estudos em homenagem a Paulo Bonavides, op. cit, p. 96. 
Ante lo expuesto, no podemos olvidar que la tradición (en el sentido que le da Hans Georg Gadamer) nos lega la noción de Estado Democrático de Derecho, representada por la idea de que este se asienta en dos pilares: derechos fundamentales-sociales y democracia. Dicho de otro modo, la Constitución programática-compromisoria es condición de posibilidad para la garantía del cumplimiento de los derechos sociales-fundamentales previstos en el texto constitucional. Sin la garantía de la posibilidad del rescate de esos derechos, a través de mecanismos de justicia constitucional, ¿cómo proteger al ciudadano, al grupo, a la sociedad, de las mayorias eventuales que se obstinan en no cumplir el texto constitucional

Por ese motivo es que la noción de Constitución compromisaria adquiere relevancia como un contrapunto a esa tempestad globalizante/neoliberal. Es el espacio de resistencia a esa especie de barbarie económica que tiene como lugar culminante la lex mercatoria. Nunca está demás reiterar que, por ejemplo, en Brasil, el así denominado Estado Social fue un simulacro. La fuerza interventora del Estado sirvió para exacerbar aún más las discrepancias sociales. Estoy convencido de que todavía es posible sostener que un texto constitucional que apunta en dirección de la corrección de tales anomalías no puede quedar relegado a un plano secundario, incluso en virtud de las nuevas características que asume la economía mundial ante el fenómeno de la globalización.

Ante lo expuesto, entiendo que el órgano encargado de realizar la jurisdicción constitucional debe tener una nueva inserción en el ámbito de las relaciones de los poderes de Estado, llevándolo a trascender las funciones de "checks and balances", mediante una actuación que tenga en cuenta la perspectiva de que los valores constitucionales poseen precedencia aún contra

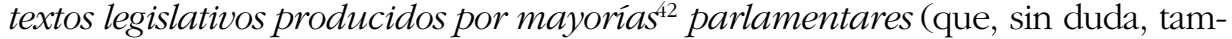
bién deben obediencia a la Constitución). Así, es absolutamente correcta la tesis de Freeman ${ }^{43}$, que entiende la Constitución como un instrumento de la soberanía democrática que no se limita a definir procedimientos para elaborar $y$ aplicar las leyes, sino que organiza y califica estos procedimientos ordinarios con el propósito de evitar la usurpación de la soberanía popular por parte de instituciones públicas o privadas.

Para los objetivos de este abordaje, importa recordar que, en términos de doctrina brasileña, Paulo Bonavides ${ }^{44}$ justifica la tesis substancialista, admitiendo, por motivos pragmáticos, la judicialización de la política —si así se quisiera denominar el fenómeno de la concretización de derechos fundamentalessociales por la vía judicial - en países en que haya un acentuado grado de

42 Ver TRIBE, Laurence. The puzzling persistence of process-based theories. Yale Law Journal, 1980 , p. 896.

43 Cfe. FREEMAN, Samuel. Original Meaning, Democratic Interpretation and the Constitution, In: Philosophy \& Public Affairs, vol. 21, n. 1, 1992, p. 13.

44 Cfe. BONAVIDES, Paulo. A Constituição Aberta. Belo Horizonte, Livraria Del Rey, 1993, p. 9-10; también ver SIQUEIRA CASTRO, Carlos Roberto de. A Constituição Aberta e Atualidades dos Direitos Fundamentais do Homem. Río de Janeiro, UERJ, mimeog. 1995, p. 20-21, además de Vianna, op. cit., p. 40-41. 
inefectividad de la Constitución (es el típico caso de Brasil). La tesis substancialista parte de la premisa de que la justicia constitucional debe asumir una actitud que, en el contexto de la tesis aquí expuesta, puede ser entendida como intervencionista, lejos, por lo tanto, de la posición absentista propia del modelo liberal-individualista-normativista que empapa la dogmática jurídica brasileña.

En cuanto al paradigma procedimental habermasiano pretende solo asegurar las condiciones necesarias, a partir de las cuales los miembros de una comunidad jurídica, por medios de prácticas comunicativas de autodeterminación, interpretan y concretizan los ideales inscriptos en la Constitución ${ }^{45}$, donde la función de la Corte Constitucional originaria o no del Poder Judicial, sería la de celar por el respeto a los procedimientos democráticos para la formación de la opinión y de la voluntad política, a partir de la propia ciudadanía, y no la de adjudicarse el papel de legislador político ${ }^{46}$, no debiendo, por lo tanto, la Corte Constitucional transformarse en guardiana de un supuesto orden suprapositivo de valores substanciales, reservándose la intervención del Poder Judicial solamente para facultar a los excluidos de la participación, el acceso directo a los "poderes políticos" ${ }^{47}$, la realidad de países de modernidad tardía - como es el caso específico de Brasil- apunta exactamente en la dirección contraria.

Tales factores, entre tantos otros que podrían ser mencionados, denotan la fragilidad y un cierto grado de utopía en las tesis procedimentalistas, las que, por su especificidad formal, están lejos de establecer las condiciones de posibilidad para la elaboración de un proyecto apto a la construcción de una concepción substancial de democracia, donde la primacía todavía es la de proceder a la inclusión social (existen más de treinta millones viviendo en la miseria, al mismo tiempo en que la Constitución establece que Brasil es una República con miras a erradicar la miseria y la desigualdad....) y el rescate de las promesas de la modernidad, emanada de la refundación de la sociedad proveniente del proceso constituyente.

\section{EL PAPEL DE LA HERMENÉUTICA EN ESE ROMPIMIENTO PARADIGMÁTICO NECESARIO Y EL NUEVO PAPEL DE LA JURISDICCIÓN CONSTITUCIONAL EN LA CONCRETIZACIÓN DE LOS DERECHOS FUNDAMENTALES-SOCIALES}

En "Cien años de Soledad", Gabriel García Márquez cuenta que, en Macondo, el mundo era tan reciente que muchas cosas carecían de nombre y para mencionarlas se precisaba señalar con el dedo. El Estado Democrático de Derecho $-\mathrm{y}$ las Constituciones que lo institucionalizaron - también son muy recientes. Observando la inmensidad de los textos constitucionales, se tiene la impresión nítida de que algunas cosas todavía no tienen nombre; los juristas se

45 Cfe. HABERMAS, Más Allá, op. cit., p.99.

46 Ídem, ibídem.

47 Ídem, ibídem. 
limitan — cuando lo hacen — a señalarlas con el dedo....La falta de una comprensión previa impide el acontecer del sentido. Gadamer siempre nos ha enseñado que la comprensión implica una pre-comprensión que, a su vez, es prefigurada por una tradición determinada en que vive el intérprete y que modela sus pre-juicios. De este modo, el intérprete del Derecho hablará el Derecho y del Derecho a partir de sus prejuicios, o sea de su precomprensión ${ }^{48}$. Esa precomprensión es producto de la relación intersubjetiva (sujeto-sujeto) que el intérprete tiene en el mundo. El intérprete no interpreta desde lo alto de una relación sujeto-objeto. Estará, sí, siempre introducido en una situación hermenéutica. Es preciso tener claro que diferentemente de otras disciplinas (o ciencias), el Derecho posee una especificidad que reside en la relevante circunstancia de que la interpretación de un texto normativo - que siempre emanará como norma- depende de su conformidad con un texto de validez superior. Se trata de la Constitución, que, más que un texto que es condición de posibilidad hermenéutica de otro texto, es un fenómeno construido históricamente como producto de un pacto constituyente, en cuanto explicitación del contrato social. La tradición nos lega varios sentidos de Constitución. Contemporáneamente, la evolución histórica del constitucionalismo en el mundo (especialmente en el continente europeo) nos coloca a disposición la noción de Constitución como detentora de una fuerza normativa, ya que es exactamente a partir de la comprensión de ese fenómeno que podremos dar sentido a la relación Constitución-Estado-Sociedad. Más que eso, es del sentido que tenemos de Constitución que dependerá el proceso de interpretación de los textos normativos del sistema.

De ahí que, una "baja comprensión" sobre el sentido de la Constitución —en lo que ella significa en el ámbito del Estado Democrático de Derechoinexorablemente acarreará una "baja aplicación", con efectivo perjuicio para la concretización de los derechos fundamentales-sociales. Las condiciones de posibilidades para que el intérprete pueda comprender un texto implican, siempre e inexorablemente, la existencia de una pre-comprensión (sus pre-juicios) acerca de la totalidad, que su lenguaje le posibilita, del sistema jurídicopolítico-social. Desde esta visión comprensiva, el intérprete formulará inicialmente sus juicios sobre el sentido del ordenamiento. Y siendo la Constitución el fundamento de la validez de todo el sistema jurídico —y esa es la especificidad mayor de la ciencia jurídica - de su interpretación/aplicación, adecuada o no, es que emanará su efectividad o inefectividad.

Caben aquí las palabras de Konrad Hesse, para quien resulta de fundamental importancia para la preservación y la consolidación de la fuerza normativa de la Constitución la interpretación constitucional, que se encuentra necesariamente sometida al mando de la optimización del texto constitucional. Se trata de un problema fundamentalmente hermenéutico.

Dicho de un modo más simple: si el intérprete posee una baja precomprensión, es decir, si el intérprete sabe poco o casi nada sobre la Constitución

48 Cfe. GADAMER, Hans-Georg. Wahrheit und Method, I, II. Tübingen, Mohr, 1990. 
- y por lo tanto, sobre la importancia de la jurisdicción constitucional, la teoría del Estado, la función del Derecho, etc.- estará condenado a la pobreza de razonamiento, quedando restringido al manejo de los viejos métodos de interpretación y del cotejo de textos jurídicos en el plano de la mera infraconstitucionalidad; por ello, no es raro que juristas y tribunales continúan interpretando la Constitución de acuerdo con los Códigos y no los Códigos de conformidad con la Constitución! ${ }^{19}$. En una palabra: para este tipo de jurista, vigencia es igual a validez, pues para ellos, texto y norma significan la misma cosa ${ }^{50}$.

No es difícil constatar que el análisis de la jurisdicción constitucional debe estar atravesado por esa perspectiva hermenéutica. Ese sesgo se hace más presente y más fuerte en el momento del examen de las cuestiones atinentes a los efectos de las decisiones de (in)constitucionalidad y de los mecanismos de la interpretación conforme (verfassungskonforme Auslegung) y de la nulidad parcial sin reducción de texto (Teilnichtigerklärung obne Normtext Reduzierung), además de la problemática que involucra la relación jurisdicción-legislación, a partir de la inexorable atribución de sentido (Sinngebung) que se presenta en las decisiones interpretativas de los tribunales brasileños y de los otros países que pueden ser utilizados como parámetros para el examen de esa problemática ${ }^{51}$. Por este motivo, insisto, en que la hermenéutica, más que contribución, se transforma en condición de posibilidad para la construcción de las condiciones de posibilidad de la elaboración de un discurso apto a desmistificar las tesis que, históricamente, oscurecieron/obstaculizaron las posibilidades transformadoras y emancipatorias del Derecho, que implican un amplio acceso a la justicia y un auténtico proceso de capilarización de la jurisdicción constitucional, donde asume especial relevancia —en países como Brasil que adoptan el sistema mixto de control de constitucionalidad- el control difuso/concreto.

49 Cabe resaltar una cuestión fundamental, que es la interpretación de los mismos textos o expresiones de textos bajo el régimen constitucional anterior y bajo el nuevo. Analizando el caso de la Constitución de España, Hernández Gil recuerda la necesidad de modificar radicalmente el lenguaje jurídico, el sistema de lenguaje o el marco de referencia jurídico de todos los operadores del Derecho de España para una comprensión adecuada del nuevo paradigma constitucional. El año 1981 puede ser considerado crucial para ese intento. En efecto, basta que se examine la correlación semántica que los juristas tenían antes y tienen ahora sobre expresiones como igualdad, discriminación. inocencia, prueba, domicilio o ley fundamental, cuyos significados sufrieron radical alteración si se los compara con la versión a-técnica y pre-técnica que tenían antes de la entrada en funcionamiento del Tribunal Constitucional. Sin la existencia de un Tribunal Constitucional, tales modificaciones no se habrían firmado con tanta solidez o, al menos, tal fenómeno no habría ocurrido con tanta rapidez. Y esto puede servir para colocar una cuestión de notable interés: el Tribunal Constitucional no solamente emplea normas de interpretación, como también las construye y las impone a la comunidad jurídica. Así, en la sentencia 64/83, impuso a los jueces y Tribunales la obligación de interpretar las leyes de conformidad con la Constitución. Cfe. HERNÁNDEZ GIL, Antonio. La justicia en la concepción del derecho según la Constitución española. In: División de Poderes y Interpretación. Hacia una teoría de la praxis constitucional. Edición y prólogo de Antonio López Pina. Madrid, Tecnos, 1987, op. cit., p. 155.

50 En el plano de la hermenéutica, a eso se le llama "entificación del ser".

51 Ver STRECK, Jurisdição Constitucional, op.cit. 
En este sentido, al analizar la problemática del Derecho y del Estado, sus crisis y las implicaciones de la revolución copernicana provocada por el constitucionalismo de la segunda posguerra, trato de incluirme en ese paradigma fenomenológico-hermenéutico. Es de este ámbito que emerge la capacidad y la posibilidad de un cuestionar que se inserta en la tradición, pero que piensa en las propias condiciones de posibilidad de la tradición.

Hay que tener bien claro que eso no es impuesto por la historicidad del sentido. Cualquier tentativa formal explicitadora de un área del Derecho implica, tácitamente, la discusión de las condiciones de historicidad del perfil de esa área. En esta dirección apuntan los presentes análisis. Ellas no se vuelcan contra aquello que es desarrollado en lo cotidiano de la racionalidad jurídica, sino que se dirigen, fundamentalmente, bacia un lugar que esa racionalidad puede silenciar, pero del cual ella se alimenta.

En una palabra: la inserción de la justicia constitucional en el contexto de la realización de los derechos fundamentales-sociales debe tener en cuenta, necesariamente, el papel asumido por la Constitución en el interior del nuevo paradigma instituido por el Estado Democrático de Derecho. Del mismo modo, la evolución de la concepción de Estado exige una ruptura con la clásica división de poderes. Es en ese contexto que surgen los Tribunales Constitucionales. Hay que comprender que, inherente al nuevo papel asumido por el Derecho transformador, a partir de la idea de fuerza normativa y de la perspectiva dirigente de la Constitución, está la admisión de un (a veces necesario) desplazamiento de la esfera de acción de los demás Poderes en dirección al Poder Judicial, específicamente, la justicia constitucional. Buscar la superación de esa crisis - que, insisto, es una crisis de paradigma - es condición de posibilidad para la construcción de un discurso jurídico apto a comprender las especificidades propias de la revolución copernicana ocurrida en el plano del derecho constitucional. No hay como discordar de los argumentos de Ferrajoli, cuando afirma que, en el Estado Democrático de Derecho, bubo una alteración en la relación entre la política y el Derecho. En efecto, el Derecho ya no está subordinado a la politica como si fuera de ella un mero instrumento, sino que es la política la que se convierte en instrumento de actuación del Derecho, subordinada a los vínculos impuestos a ella por los principios constitucionales: vínculos negativos, como los generados por los derechos a las libertades que no pueden ser violados; vínculos positivos, como los generados por los derechos sociales, que deben ser satisfechos ${ }^{52}$.

52 Cfe. FERRAJOLI, Luigi. Jueces y política. Derechos y Libertades. In: Revista del Instituto Bartolomé de las Casas. Año IV. Enero, 1999, n. 7. Madrid, Universidad Carlos III. Esto implica emprender una cierta radicalidad en la aplicación de la jurisdicción constitucional, alcanzando incluso el derecho penal en aquello que se ha denominado prohibición de protección deficiente (Untermassverbot). En la visión perspicaz de Carlos Bernal Pulido, este concepto se refiere a la estructura que el principio de proporcionalidad adquiere en la aplicación de los derechos fundamentales de protección. La prohibición de protección deficiente puede definirse como un criterio estructural para la determinación de los derechos fundamentales, con cuya aplicación puede determinarse si un acto estatal — por antonomasia una omisión — vulnera un derecho fundamental de 


\section{A MODO DE CONCLUSIÓN}

Ya en el lejano año de 1945, el jurista Werner Kägij3 clamaba: Sage mir Deine Einstellung zur Verfassungsgerichtsbarkeit und ich sage Dir, man für einen Verfassungsbegriff Du hast . La aseveración de Kägi, que condicionaba el sentido de Constitución a lo que pensamos sobre el papel de la jurisdicción constitucional, aún hoy encuentra resonancia cuando se pretende discutir la problemática referente a la (in)efectividad de la Constitución.

La segunda posguerra fue sobremanera generosa para con el derecho constitucional. En efecto, mientras el constitucionalismo es atravesado por una verdadera revolución copernicana, inaugurando una fase que puede ser denominada de pospositivismo - como bien dice el jurista brasileño Pauto Bonavies, antes triunfaron los códigos, boy triunfan las Constituciones- los textos constitucionales más que fundamento de validez superior del ordenamiento, pasan a consubstanciar la propia actividad político-estatal, a partir del establecimiento de los derechos fundamentales-sociales y de los mecanismos para su concretización.

Esta revolución copernicana no estaría completa sin una nueva mirada sobre la jurisdicción constitucional, que pasa a ser la condición de posibilidad del Estado Democrático de Derecho. Por lo tanto, las posibilidades de efectivación de los derechos previstos en los textos constitucionales pasan a depender del proceso de comprensión del significado de ese nuevo paradigma jurídico-político.

En ese contexto, los conceptos de soberanía popular, separación de poderes y mayorías parlamentarias dan lugar a la legitimidad constitucional, establecedora de un constituir de la sociedad. Es decir, del modelo de Constitución formal, en cuyo interior el derecho asumía un papel de ordenamiento, se llega a la revalorización del Derecho, que pasa a ejercer un papel de transformación de la realidad de la sociedad, superando, incluso, el modelo del Estado Social. Es para este salto paradigmático que debe estar atento el jurista.

protección. In: El principio de proporcionalidad y los derechos fundamentales. Madrid, CEPC, 2003, p. 799. En Brasil no hay noticia sobre la aplicación del principio de prohibición de protección deficiente. Sin embargo, existen varias hipótesis de aplicación necesaria, como es el caso de la ley que estableció como causa de extinción de punibilidad en los crímenes de violación, el casamiento de la víctima con tercera persona (ver parecer de mi autoría en el proceso n. 700006451827), que tramita ante la $5^{\text {a }}$ Cámara Criminal del Tribunal de Justicia de Rio Grande do Sul) y el pago del tributo como causa de extinción de la punibilidad en los casos de delito fiscal (ADIn 3002, propuesta por el Procurador General de la República ante el Supremo Tribunal Federal), para citar solamente dos ejemplos. Sobre un análisis del bien jurídico a partir de la materialidad de la Constitución, ver STRECK, Lenio Luiz y FELDENS, Luciano. Crimen y Constitución. La legitimidad de la función investigatoria del Ministerio Público. Río de Janeiro, Forense, 2003.

53 Cfe. KÄGI, Werner. Die Verfassung als rechliche Grundordnung des Saates. Untersuchungen über die Entwicklungstendenz im modernen Verfassungsrecht. Zurich: Polygraphischer Verlag, 1945, p. 147.-(Dime tu posición sobre la jurisdicción constitucional y yo te diré qué concepto tienes de la Constitución). 
Ese paradigma toma forma cuando la libertad de conformación del legislador, pródiga en discrecionalidad en el Estado-Liberal, empieza a ser contestada de dos modos: de un lado, los textos constitucionales dirigentes y compromisarios que apuntan hacia el deber de concretizar los derechos fundamentales y sociales; de otro lado, el control por parte de los tribunales, que pasaron no solo a decidir sobre la forma procedimental de la acción de las leyes, sino también sobre su contenido material, incorporando los valores previstos en la Constitución.

Está, entonces, el prevalecimiento del principio de la constitucionalidad sobre el principio de la mayoría, lo que significa entender la Constitución como un remedio contra mayorías. Por lo tanto, la noción de un tercer modelo de derecho, el Estado Democrático de Derecho, lleva en consideración la noción de Constitución como valores a ser realizados, emanados del contrato social. $\mathrm{La}$ Constitución surge, en este tercer modelo/paradigma, no solamente como la explicitación del contrato social, sino, más que eso, con su fuerza normativa de constituir-la-acción del Estado.

Cuando aquí se afirma que la Constitución es la explicitación del contrato social, se está afirmando el carácter discursivo que asume la noción de Constitución, en cuanto producto de un proceso constituyente ${ }^{54}$. La noción de Constitución, implícita en el modelo de Estado Democrático de Derecho, y de la función de la justicia constitucional como garantizadora de la fuerza normativa substancial del texto constitucional, está umbilicalmente ligada a la noción de contrato social. De allí la necesidad de advertir sobre el hecho de que la Constitución, entendida como explicitación del contrato, no puede ser comprendida, meramente, como un "contrato" que se establece, como una tercera cosa que se interpone entre el Estado, el Poder y el Gobierno, con los destinatarios, el pueblo, la sociedad; antes que eso, el lenguaje constituyente pasa a ser condición de posibilidad de lo nuevo, en la medida en que, en la tradición del Estado Democrático de Derecho, el constitucionalismo supera al modelo del paradigma liberal, pasando a representar el modo por el cual se realizará el rescate de las promesas de la modernidad.

Ante lo expuesto, entiendo que existe un nuevo papel reservado a la jurisdicción constitucional en el interior de este nuevo paradigma, reservándosele una nueva forma de inserción en el ámbito de las relaciones de los poderes de Estado, llevándolo a trascender las funciones de "checks and balances", mediante una actuación que tenga en cuenta la perspectiva de que los valores constitucionales tienen precedencia incluso contra textos legislativos producidos por mayorias eventuales.

Siempre se podrá decir —y este es uno de los puntos preponderantes de la discusión entre defensores de las tesis procedimentalistas y substancialistas-

54 No se ignora el modo de producción de la Constitución alemana de 1949, que no pasó por un proceso constituyente. Tal circunstancia, sin embargo, no perjudicó su efectividad, exactamente por la presencia del Bundesverfassungsgericht, que, con su papel interventivo, promovió una amplia mutación constitucional, sirviendo de inspiración para los demás países europeos que adoptaron la fórmula de tribunales ad-hoc. 
que a los tribunales les falta la legitimidad política y los instrumentos básicos necesarios para la implementación de las políticas del bienestar social. En este aspecto, importa registrar que la tesis, aquí sufragada, de que la jurisdicción constitucional, además de representar un importantísimo mecanismo político de control de los poderes del Estado, puede/debe ser —en la inercia de los poderes ejecutivo y legislativo- el locus privilegiado para la realización de los derechos fundamentales sociales, no deja de tener en cuenta las diferencias existentes entre los modelos de jurisdicción constitucional practicados en Brasil y en los diversos países europeos, en especial aquellos que adoptaron la fórmula de los tribunales aad-hoc (tribunales que no componen la cúpula del Poder Judicial).

Parece no haber dudas de que el modelo de tribunales ad hoc consigue dar respuestas mucho más satisfactorias al problema resultante del tensionamiento entre derecho y política y sobre la cuestión de la legitimidad. Tal vez el establecimiento de los Tribunales Constitucionales haya sido la respuesta más adecuada a lo aseverado por Werner Kägi, cuando condicionó el sentido de Constitución a aquello que pensamos acerca del significado y de la función de la jurisdicción constitucional. De allí la feliz conceptuación de Javier Pérez Royo 55 .

El Tribunal Constitucional europeo es un órgano artificial inventado por el constituyente democrático del siglo xx para completar la división tripartita clásica de poderes ante la insuficiencia de esta última para controlar el ejercicio del poder del Estado y evitar su desnaturalización autoritaria. Se trata, pues, de un producto de la falta de respeto a la Constitución por los poderes clásicos del Estado... los constituyentes democráticos de los países en los que ha ocurrido esto último han tenido que hacer de la necesidad virtud...En esto, en última instancia, es en lo que consiste un Tribunal Constitucional.

Evidentemente, cuando estoy hablando de una función intervencionista de la justicia constitucional, no estoy proponiendo una judicialización simplista de la política y de las relaciones sociales y ni siquiera la muerte de la política ${ }^{56}$. Tampoco se defiende, como bien subraya García Herrera, la transformación de la magistratura en sujeto político, ni se propugna recuperar la pugna entre Constitución y Ley, marginando el Parlamento y transformando el juez en protagonista principal del desarrollo constitucional; antes bien, la apelación a jurisdicción (constitucional) no se confronta con la relación Ley-Constitución, sino que se asienta en la fase del desarrollo constitucional en el que nos encontramos caracterizada por la contradicción entre los valores constitucionales y las

55 Cfe. PÉREZ ROYO, Javier. Curso de Derecho Constitucional. 6. ${ }^{a}$ Ed. Madrid, 1999.

56 Como bien señala Bruce Ackerman, al tratar la problemática norteamericana, declarando inconstitucional un determinado dispositivo legal, el Tribunal está desempeñando una función dualista crítica. El mismo está indicando a la masa de ciudadanos privados que algo especial está ocurriendo en los corredores del poder; que sus pretendidos representantes están tratando de legislar con poca credibilidad; y que, una vez más, ha llegado el momento de determinar si nuestra generación responderá haciendo el esfuerzo político requerido para redefinir, como ciudadanos privados, nuestra identidad colectiva. Cfe. ACKERMAN, op. cit., p.203. 
propuestas alternativas con motivo de la crisis del Estado social, y por la pérdida de substantividad de la Ley que deja unos márgenes de decisión que deben ser llenados con y desde la Constitución, desde sus derechos y decisiones fundamentales: "Enlazando con las premisas antes enunciadas, el significado de la jurisdicción no puede desligarse de las características de una Constitución asentada en un pacto contradictorio, basada en contenidos materiales, traspasada por valores contrapuestos pero apuntada hacia la consecución de objetivos de igualdad substancial, aunque haya algunos principios de consenso universal (dignidad, democracia) ${ }^{57}$.

O sea, cuando clamo por un cierto grado de intervencionismo de cuño substancialista, me refiero al cumplimiento de los preceptos y principios inherente a los Derechos Fundamentales-Sociales ${ }^{58}$ y al núcleo político del Estado Social inmanente al paradigma del Estado Democrático de Derecho establecido en los textos constitucionales de la segunda posguerra. Esto implica asumir la tesis - y Andreas Krell ${ }^{59}$ apunta correctamente para esa dirección-, de que, allá donde el proceso político (Legislativo, Ejecutivo) falla o se omite en la implementación de políticas y de los objetivos sociales en ella implicados, cabe $a$ la justicia constitucional tomar una actitud activa en la realización de esos fines sociales de la corrección de prestaciones de los servicios sociales básicos.

No se puede ignorar que tales cuestiones pueden tropezar con lo que se denomina "financieramente posible" y en la (de)limitación del ámbito político de la esfera de competencia. Cabe, en este aspecto, la lección de Cristina Quei$\mathrm{roz}^{60}$, para quien cuando existe un derecho, este se muestra siempre como justiciable. Sucede que, a veces, en el caso de los derechos de naturaleza económica y social, estos incluso necesitan una configuración jurídica particular que sea llevada a cabo por el legislador. La "reserva de lo posible", "en el sentido de aquello que el individuo puede razonablemente exigir de la sociedad" (BverfGE 33, 303, 333; 43, 291, 314) no tiene como consecuencia su ineficacia

57 Cfe. GARCÍA HERRERA, Miguel Ángel. Poder judicial e Estado social. In: Corrupción y Estado de Derecho — el papel de la jurisdicción. Perfecto Andrés IBÁÑEZ (Editor). Madrid, Trotta, 1999, p. 83 .

58 En este sentido, Sarlet, por ejemplo, entiende que el art. 5. ${ }^{\circ}$, párrafo $1 .^{\circ}$, de la Constitución brasileña, impone a los órganos estatales la tarea de "maximizar la eficacia de los Derechos Fundamentales". Cfe. Os Direitos Fundamentais Sociais na Constituição de 1988. In: SARLET, Ingo (org.). O Direito Público em Tempos de Crise. Porto Alegre, Livraria do Advogado, 1999, p. 130.

59 Cfe. KRELL, Andréas Joachim. Realização dos Direitos Fundamentais Sociais Mediante Controle Judicial da Prestação dos Serviços Públicos Básicos. Anuário dos Cursos de Pós-Graduação em Direito. n.10. Recife: UFPE, 2000, p. 56-57.

60 Cfe. QUEIROZ, Cristina. Interpretação e Poder Judicial — sobre a epistemologia da construção constitucional. Coimbra, Coimbra Editora, 2000, p. 65. Ver, con este propósito, la siguiente sentencia del Tribunal Constitucional de Portugal: "Todo este complexo normativo, que não é meramente programático e contém antes uma vinculação para o legislador ordinário, não pode desprender-se de princípios fundamentais consagrados na Constituição como seja o empenhamento da República 'na construção de uma sociedade livre, justa e solidária', o objetivo da 'realização da democracia econômica, social e cultural', as tarefas fundamentais do Estado de promover 'a efectivação dos direitos econômicos, sociais e culturais' e assegurar 'o ensino e a valorização permanente'". Ac. TC 148/94. 
jurídica. Esa cláusula expresa únicamente la necesidad de su ponderación. Konrad Hesse habla, con este propósito, de una "obligación positiva" de "hacer todo para la realización de los derechos fundamentales, aún cuando no exista ningún derecho subjetivo por parte de los ciudadanos".

Por esto, basado en García Herrera, propugno una resistencia constitucional en cuanto a política del Derecho encaminada a salvaguardar la vigencia y la eficacia del proyecto constitucional. Con la resistencia constitucional se intenta conseguir un doble objetivo: por una parte, suplir las carencias materiales de la Ley, ya sea en su vertiente de indefinición programática, ya sea en su aspecto de esquema procedimental, apelando, en última instancia, a los contenidos consagrados constitucionalmente y, por otra parte, salvaguardar la vocación transformadora consubstancial a la Constitución que, sin merma de los espacios de desarrollo político consentidos al legislador, establece una estructura de proyecto ideal que debe presidir la resolución del conflicto, sobre todo en aquellos temas referidos a los derechos sociales, apertura del sistema e integración de nuevas demandas ${ }^{61}$.

Propugnar la resistencia constitucional significa detectar el conflicto entre principios constitucionales y la inspiración neoliberal que promueve la implantación de nuevos valores que entran en contradicción con aquellos: solidaridad frente al individualismo, programación frente a competitividad, igualdad substancial frente a mercado, dirección pública frente a procedimientos pluralistas $^{62}$.

Este proceso de resistencia constitucional - que, para mí, pasa a ser un compromiso ético de los juristas - supera el esquema de igualdad formal rumbo a la igualdad material, implicando, entre otras tareas, la utilización de forma amplia, de los mecanismos de acceso a la justicia, a través de la jurisdicción constitucional, en sus más variadas formas (control de constitucionalidad, writs constitucionales, filtrado hermenéutico constitucional, con la utilización de decisiones de verfassungskonforme Auslegung, Teilnichtigerklärung obne Normtext Reduzierung, el apelo al legislador, etc.), buscando el cumplimiento no solo del respeto a los derechos fundamentales de defensa, sino también a la efectiva implantación de los derechos sociales prestacionales. Por eso, se torna relevante la discusión de las condiciones de posibilidad que tienen los juristas para la construcción de un discurso (crítico) que apunte hacia la superación de la crisis paradigmática y la implementación de los valores constitucionales.

Entonces, somos juristas ¿para qué? Hacemos Derecho ¿para quién? ¿Cuál es la función de la justicia constitucional, en fin, del Poder Judicial? Parece que Andréas Krell posee una respuesta absolutamente adecuada a esas preguntas, cuando asevera que es obligación de un Estado Social — fórmula cons-

61 Cfe. GARCÍA HERRERA, op.cit.

62 Consultar GARCÍA HERRERA, Miguel Angel. Poder Judicial y Estado Social: Legalidad y Resistencia Constitucional. In: Corrupción y Estado de Derecho-El papel de la jurisdicción. Perfecto Andrés IBÁÑEZ (Editor). Madrid, Editorial Trotta, 1996, p.83. 
tante en los principales textos constitucionales de la segunda posguerra- controlar los riesgos resultantes del problema de la pobreza, que no pueden ser adjudicados a los propios individuos y restituir un status mínimo de satisfacción de las necesidades personales. En una sociedad donde existe la posibilidad fáctica de la cura de una enfermedad, su impedimento significa una violencia contra la persona enferma que es directamente perjudicada en su vida e integridad (Helmut Willke). De esta manera, los Derechos Fundamentales de la primera generación fueron tomados como fuentes de derechos subjetivos a prestaciones positivas del Estado. Por eso, he concluido, que las cuestiones ligadas al cumplimiento de las tareas sociales como la formulación de las respectivas políticas en el Estado Democrático (y Social) de Derecho, no están relegadas solamente al gobierno y a la administración (Gilberto Bercovici), sino que tienen su fundamento en las propias normas constitucionales sobre derechos sociales; su observación por el Poder Ejecutivo puede y debe ser controlada por el Poder Judicial ${ }^{63}$.

En síntesis: hay que construir nuevos caminos en busca de la concretización de las promesas de la modernidad plasmadas en el texto constitucional. Como en el Macondo de Gabriel García Márquez, algunas "cosas" de los derechos fundamentales sociales y de los textos constitucionales todavía están siendo señaladas con el dedo, porque todavía no tienen la "nominación constitucionalizante». Viejos prejuicios continúan causando perjuicios. Tal vez en la imbricación entre jurisdicción constitucional y participación de la sociedad esté el camino para lo nuevo, para la superación de la crisis, que, como se sabe, existe exactamente cuando lo nuevo no nace y lo viejo no muere; en fin, cuando lo viejo oscurece lo nuevo. Por eso, igualmente debemos superar la dicotomía judicialización de la política-politización de lo jurídico, porque, como bien señala Gisele Cittadino ${ }^{64}$;la tarea de concretizar los derechos fundamentalessociales es de responsabilidad de una ciudadania juridicamente participativa que depende, es verdad, de la actuación de los tribunales y de la jurisdicción constitucional, pero, sobretodo, del nivel de presión y movilización politica que, sobre ellos, se haga!

63 Cfe. KRELL, op. cit., p. 41 e 55.

64 Cfe. CITTADINO, Gisele. Judicialização da política, constitucionalismo democrático e separação de poderes. In: VIANNA, Luiz Werneck (Org.). A democracia e os Três Poderes no Brasil. Río de Janeiro: UFMG, IUPERJ, FAPERJ, 2002, p.39. 